\title{
Compliance with American College of Chest Physicians (ACCP) recommendations for thromboembolic prophylaxis in the intensive care unit: a level I trauma center experience
}

Michael J. Waxman ${ }^{1}$, Daniel Griffin², Erica Sercy ${ }^{3}$ and David Bar-Or ${ }^{3,4^{*}}$

\begin{abstract}
Background: Recommendations are for nearly universal venous thromboembolism (VTE) prophylaxis in critically ill hospitalized patients because of their well-recognized risks. In those intensive care units (ICUs) where patient care is more uniformly directed, it may be expected that VTE prophylaxis would more closely follow this standard over units that are less uniform, such as open-model ICUs.
\end{abstract}

Methods: This was a retrospective cohort study on all patients aged 18+ admitted to an open ICU between 6/1/ 2017 and 5/31/2018. Patients were excluded if they had instructions to receive comfort measures only or required therapeutic anticoagulant administration. Prophylaxis administration practices, including administration of mechanical and/or pharmacologic prophylaxis and delayed ( $\geq 48 \mathrm{~h}$ post-ICU admission) initiation of pharmacologic prophylaxis, were compared between patients admitted to the ICU by the trauma service versus other departments. Root causes for opting out of pharmacological prophylaxis were documented and compared between the two study groups.

Results: One-hundred two study participants were admitted by the trauma service, and 98 were from a nontrauma service. Mechanical (98\% trauma vs. $99 \%$ non-trauma, $P=0.99)$ and pharmacologic ( $54 \%$ vs. 44\%, $P=0.16$ ) prophylaxis rates were similar between the two admission groups. The median time from ICU admission to pharmacologic prophylaxis initiation was $53 \mathrm{~h}$ for the trauma service and $10 \mathrm{~h}$ for the non-trauma services $(P \leq$ 0.01). In regression analyses, trauma-service admission (odds ratio $(\mathrm{OR})=2.88,95 \%$ confidence interval $(\mathrm{Cl}) 1.21-6.83$ ) and increasing ICU length of stay $(\mathrm{OR}=1.13,95 \% \mathrm{Cl} 1.05-1.21)$ were independently associated with pharmacologic prophylaxis use. Trauma-service admission $(\mathrm{OR}=8.30,95 \% \mathrm{Cl} 2.18-31.56)$ and increasing hospital length of stay $(\mathrm{OR}=1.15,95 \% \mathrm{Cl} 1.03-1.28)$ were independently associated with delayed prophylaxis initiation.

\footnotetext{
* Correspondence: davidbme49@gmail.com

${ }^{3}$ Trauma Research Department, Research Medical Center, Kansas City, MO, USA

${ }^{4}$ Injury Outcomes Network and Trauma Research LLC, 501 E. Hampden Avenue, Room 4-454, Englewood, Colorado 80113, USA

Full list of author information is available at the end of the article
}

(C) The Author(s). 2021 Open Access This article is licensed under a Creative Commons Attribution 4.0 International License, which permits use, sharing, adaptation, distribution and reproduction in any medium or format, as long as you give appropriate credit to the original author(s) and the source, provide a link to the Creative Commons licence, and indicate if changes were made. The images or other third party material in this article are included in the article's Creative Commons licence, unless indicated otherwise in a credit line to the material. If material is not included in the article's Creative Commons licence and your intended use is not permitted by statutory regulation or exceeds the permitted use, you will need to obtain permission directly from the copyright holder. To view a copy of this licence, visit http://creativecommons.org/licenses/by/4.0/ The Creative Commons Public Domain Dedication waiver (http://creativecommons.org/publicdomain/zero/1.0/) applies to the data made available in this article, unless otherwise stated in a credit line to the data. 
(Continued from previous page)

Conclusions: Overall, the receipt of VTE prophylaxis of any type was close to $100 \%$, due to the nearly universal use of mechanical compression devices among ICU patients in this study. However, when examining pharmacologic prophylaxis specifically, the rate was considerably lower than is currently recommended: $54 \%$ among the trauma services and 44\% among non-trauma services.

Keywords: Venous thromboembolism, Chemoprophylaxis, Intensive care unit,

\section{Background}

Patients in the intensive care unit (ICU) are at increased risk for venous thromboembolism (VTE), the most common preventable cause of hospital death in the United States [1, 2], because of their risk factors, including immobility, frequency of endothelial injury from trauma and surgical procedures, and an increased likelihood of underlying disorders related to thrombophilic states [3-8]. Indeed, a previous study showed that almost all patients in a critical care unit had at least one major VTE risk factor, and a large proportion had multiple factors [9]. The frequencies of the two types of VTE, deep vein thrombosis and pulmonary embolism, in patients admitted to an ICU have been estimated at $5-31 \%$ and $0.4-2.3 \%$, respectively [10-12].

Current recommendations of the American College of Chest Physicians (ACCP) include administration of pharmacologic VTE prophylaxis initiated as soon as possible upon ICU admission, unless the patient is at high risk of bleeding [13, 14]. Mechanical prophylaxis may alternatively be used if pharmacologic prophylaxis is deemed unsafe or specific contraindications exist [15-17]. Because VTE prophylaxis agents, including heparin, low molecular weight heparin (LMWH), fondaparinux, and direct oral anticoagulants $[18,19]$, have been shown to increase bleeding risk, choice and timing of administration should weigh the benefit of VTE prevention against a patient's risk of bleeding [15-17, 20-23]. It is also vital that dosing of VTE prophylaxis is consistent, as missed doses significantly increase the risk of VTE [14, 24].

The structure of the ICU might be an important factor in VTE prophylaxis administration practices. Generally, ICUs are organized as either open, allowing any physician to admit, care for, and discharge patients, or closed, with those same functions relegated to only a few individuals, usually critical care physicians that are all part of the same group. Some ICUs have segments of their care closed to certain physicians, and other parts of the care are open. An example of this latter structure would be a single-group trauma service operating side-by-side with medical ICU patients whose attending physicians belong to a number of different groups.

Seven years before the current study, a quality improvement (QI) project at our tertiary care medical center's medical and surgical ICUs assessed the prevalence of VTE prophylaxis treatment as various interventions were introduced. At the outset of the QI study, VTE prophylaxis, either pharmacologic or mechanical, was prescribed $42 \%$ of the time. With a widespread education campaign and placement of prophylaxis options on all ICU order sets, the rate increased to $\sim 48 \%$. Once a default order mandating the use of mechanical compression devices except where contraindicated (severe bilateral lower extremity trauma) was passed through the medical staff, the prophylaxis rate increased to over $90 \%$. That default order was still present at the time of our current study.

The purpose of this study was to examine the VTE prophylaxis rates of patients in the ICU of this single medical center, compare pharmacologic prophylaxis to mechanical device rates, and compare those rates between the more uniformly managed single-group trauma-surgery service to patients cared for by nontrauma-surgeon physicians from multiple groups who practice in the ICU. We hypothesized that the "closed" trauma service would demonstrate a higher rate of pharmacologic VTE prophylaxis than a group of patients managed by multiple physicians from different groups practicing in the open-model medical-surgical ICU. Mechanical prophylaxis rates were also examined, but it was postulated that these rates would be high in both groups.

\section{Methods}

This was a retrospective cohort study of patients age 18 years and older admitted to a 32-bed medical-surgical ICU (16-bed medical, 16-bed surgical) over the period 6/ $1 / 2017$ to $5 / 31 / 2018$. The study aim was to examine differences two primary outcomes-administration of pharmacologic prophylaxis (yes/no) and delayed initiation of pharmacologic prophylaxis administration (yes/ no), defined as initiation $\geq 48 \mathrm{~h}$ after ICU admission-according to ICU admission service, categorized as trauma service vs. non-trauma service. Admission service was considered the primary exposure variable. Receipt of mechanical prophylaxis was also examined between the two study groups. All patients admitted to the ICU during the study period were eligible for study inclusion. Patients were excluded from the study if case notes indicated they were admitted to the ICU with instructions to 
receive comfort measures only or if they were admitted for a reason requiring therapeutic administration of anticoagulants (e.g., pre-existing DVT, PE, or acute myocardial infarction). The study population was comprised of a random sample of 100 patients admitted to the ICU by the trauma service and a random sample of 100 patients admitted by non-trauma-service physicians. Although the non-trauma-service physicians were from a number of different groups, their patients are referred to as a single group for analysis purposes. This study was approved by the Institutional Review Board at the participating facility and received a waiver of HIPAA authorization and informed consent. Study data were obtained from the facility's trauma registry and patient electronic medical records.

The trauma service has a daily program during traumaphysician-led multidisciplinary rounds of reviewing mechanical and pharmacologic prophylaxis on all ICU trauma patients. A monthly trauma QI program reviews any patients who did not receive pharmacologic prophylaxis, had missing doses of prophylactic anticoagulants, or lacked mechanical prophylaxis and subsequently reports out to the monthly Trauma Morbidity and Mortality meeting attended by all trauma surgeons and various other consulting physicians and administrative personnel.

During the study period, an automated order was in place for mechanical prophylaxis to be initiated on all patients upon admission to the ICU. Ordering providers had to opt-in for pharmacologic prophylaxis at their discretion. The mechanical prophylaxis method used in the ICU was sequential compression devices, and the pharmacologic prophylaxis types administered during the study were enoxaparin, heparin, and apixaban.

Clinical descriptors collected included age, gender, race, service admitting to the ICU (trauma service or non-trauma service), primary hospital admission diagnosis, including further categorization into traumatic injury versus any other diagnosis, comorbidities (hypertension, smoking, diabetes, liver disease/disorder, obesity, history of VTE, kidney disease/disorder, cancer), admission Glasgow Coma Scale (GCS) score, pre-admission anticoagulants, and any clotting- or bleeding-related complications occurring during the ICU stay (e.g., DVT, PE, intracranial hemorrhage, surgical site bleed). Detailed information about prophylaxis administration was also collected: administration of VTE prophylaxis (mechanical or pharmacologic) during the ICU stay; start and stop times of prophylaxis; type of prophylaxis administered (mechanical, pharmacologic, or both); type of pharmacologic prophylaxis administered, if applicable (enoxaparin, heparin, or apixaban); sequence of prophylaxis administration (mechanical to pharmacologic, as well as various types of pharmacologic to each other); and whether a patient experienced any interruptions in prophylaxis administration during which they received no prophylaxis of any type after prior initiation. Additionally, if documented in the electronic medical record, the reasons for any delayed initiation or interruption of prophylaxis were recorded.

Patient demographics and clinical characteristics were described in the ICU population, and differences between trauma-service and non-trauma-service ICU admissions were evaluated using chi-square tests for categorical variables and Wilcoxon rank-sum tests for continuous variables because of non-normal distribution. Prophylaxis administration practices were described in the ICU, and these practices were compared between trauma-service and non-trauma-service admissions using chi-square tests. Rates of clotting- and bleedingrelated complications were also described in the ICU population and compared between trauma-service and non-trauma-service admissions using chi-square tests. Unadjusted and adjusted logistic regression models were used to identify factors associated with two outcomes: administration of pharmacologic prophylaxis and delayed pharmacologic prophylaxis initiation $(\geq 48 \mathrm{~h}$ after ICU admission). Adjusted models evaluated ICU admission service (trauma service vs. non-trauma service) as the primary exposure variable and additionally considered the following variables for potential inclusion as covariates: patient age, sex, race, hospital length of stay, ICU length of stay, pre-admission anticoagulants, comorbidities, and primary hospital admission diagnosis. Stepwise selection with entry criteria of $\alpha=0.20$ and exit criteria of $\alpha=0.05$ was used to determine the final adjusted model.

\section{Results}

A total of 200 patients were included in this study, of which the trauma service oversaw 102, and 98 of which were overseen by non-trauma-service physicians (Table 1). Of the non-trauma-service admissions, 42 (43\%) were admitted from the medical department, 22 (22\%) were from neurosurgery, 21 (21\%) were from cardiology, 7 (7\%) were non-neurosurgical surgery patients, 3 (3\%) were from nephrology, 1 (1\%) was from burn services, 1 (1\%) was from pulmonology, and $1(1 \%)$ was from another non-surgical department.

The median (IQR) age of the patient population was 59 (39-74) years, and $138(70 \%)$ were male (Table 1$)$. The median (IQR) total hospital length of stay was 6 (3-10) days, and the median (IQR) ICU length of stay was $3(1-5)$ days. Twenty-six percent $(n=34)$ of patients were on anticoagulants before hospital admission. Forty-two percent $(n=82)$ of patients had pre-existing hypertension, $17 \%(n=33)$ were current smokers, and 13\% $(n=25)$ had diabetes. The most common reasons for hospital admission were traumatic injury (55\%), cardiovascular disease (11\%), and headache, 
Table 1 Characteristics of the intensive care unit patient population

\begin{tabular}{|c|c|c|c|c|}
\hline & $\begin{array}{l}\text { All } \\
n=200\end{array}$ & $\begin{array}{l}\text { Trauma service } \\
n=102\end{array}$ & $\begin{array}{l}\text { Non-trauma service } \\
n=98\end{array}$ & $\mathbf{P}$ \\
\hline \multicolumn{5}{|l|}{ Patient demographics } \\
\hline Age, years, median (IQR) & $59(39-74)$ & $52(29-65)$ & $65(54-75)$ & $<0.01$ \\
\hline Sex & & & & 0.08 \\
\hline Male & $138(70 \%)$ & $75(76 \%)$ & $63(64 \%)$ & \\
\hline Female & $59(30 \%)$ & $24(24 \%)$ & 35 (36\%) & \\
\hline Race & & & & 0.21 \\
\hline White & $126(63 \%)$ & $62(61 \%)$ & $64(65 \%)$ & \\
\hline Black & $64(32 \%)$ & $37(36 \%)$ & $27(28 \%)$ & \\
\hline Other/unknown & $10(5 \%)$ & $3(3 \%)$ & $7(7 \%)$ & \\
\hline \multicolumn{5}{|l|}{ Clinical descriptors } \\
\hline Hospital length of stay, days, median (IQR) & $6(3-10)$ & $6(2-10)$ & $5(3-9)$ & 0.47 \\
\hline ICU length of stay, days, median (IQR) & $3(1-5)$ & $3(2-4)$ & $3(1-6)$ & 0.94 \\
\hline Pre-admission anticoagulants & $34(26 \%)$ & $13(20 \%)$ & $21(32 \%)$ & 0.14 \\
\hline \multicolumn{5}{|l|}{ Comorbidities } \\
\hline Hypertension & $82(42 \%)$ & $34(34 \%)$ & $48(49 \%)$ & 0.04 \\
\hline Current smoker & $33(17 \%)$ & $27(27 \%)$ & $6(6 \%)$ & $<0.01$ \\
\hline Diabetes & $25(13 \%)$ & $11(11 \%)$ & $14(14 \%)$ & 0.50 \\
\hline Liver disease & $12(6 \%)$ & $9(9 \%)$ & $3(3)$ & 0.08 \\
\hline Obesity & $12(6 \%)$ & $1(1 \%)$ & $11(11 \%)$ & $<0.01$ \\
\hline History of VTE & $4(2 \%)$ & $1(1 \%)$ & $3(3 \%)$ & 0.31 \\
\hline Chronic kidney disease & $3(1.5 \%)$ & $0(0 \%)$ & $3(3 \%)$ & 0.12 \\
\hline Cancer & $2(1 \%)$ & $0(0 \%)$ & $2(2 \%)$ & 0.25 \\
\hline Presence of traumatic injury & & & & $<0.01$ \\
\hline Yes & $110(55 \%)$ & $95(93 \%)$ & $15(15 \%)$ & \\
\hline No & $90(45 \%)$ & $7(7 \%)$ & $83(85 \%)$ & \\
\hline Primary hospital admission diagnosis & & & & $<0.01$ \\
\hline Head or facial injury & $57(29 \%)$ & $43(43 \%)$ & $14(15 \%)$ & \\
\hline Injuries of the thorax, abdomen, or neck & $39(20 \%)$ & $38(38 \%)$ & $1(1 \%)$ & \\
\hline Cardiovascular disease & $21(11 \%)$ & $2(2 \%)$ & $19(20 \%)$ & \\
\hline Extremity injuries, including hip injuries & $15(8 \%)$ & $14(14 \%)$ & $1(1 \%)$ & \\
\hline Headache, fatigue, altered mental state & $13(7 \%)$ & $0(0 \%)$ & $13(14 \%)$ & \\
\hline Musculoskeletal, connective tissue, nervous system diseases, convulsions & $9(5 \%)$ & $0(0 \%)$ & $9(9 \%)$ & \\
\hline Respiratory condition or trouble breathing & $8(4 \%)$ & $1(1 \%)$ & $7(7 \%)$ & \\
\hline Neoplasm & $7(4 \%)$ & $0(0 \%)$ & $7(7 \%)$ & \\
\hline Chest pain & $7(4 \%)$ & $0(0 \%)$ & $7(7 \%)$ & \\
\hline Digestive issues or abdominal pain & $5(3 \%)$ & $0(0 \%)$ & $5(5 \%)$ & \\
\hline Asphyxiation, burns, poisoning & $4(2 \%)$ & $1(1 \%)$ & $3(3 \%)$ & \\
\hline Complications of prosthetic devices, implants or grafts & $2(1 \%)$ & $0(0 \%)$ & $2(2 \%)$ & \\
\hline Endocrine, nutritional, or metabolic diseases & $2(1 \%)$ & $0(0 \%)$ & $2(2 \%)$ & \\
\hline Infectious disease & $2(1 \%)$ & $0(0 \%)$ & $2(2 \%)$ & \\
\hline Rash & $2(1 \%)$ & $0(0 \%)$ & $2(2 \%)$ & \\
\hline Unspecified hemorrhage, unspecified pain & $2(1 \%)$ & $1(1 \%)$ & $1(1 \%)$ & \\
\hline
\end{tabular}


fatigue, or altered mental state (7\%). The majority (93\%, $n=95)$ of patients admitted to the ICU by the trauma service had traumatic injuries, and $15(15 \%)$ patients admitted by a non-trauma-service physician had traumatic injuries.

The overall VTE prophylaxis rate in the ICU, including mechanical and pharmacologic, was 99\% (101 of 102) for the trauma service and 100\% (98 of 98) for the non-trauma-service patients $(P=0.99$, Table 2$)$. The overall administration rate of pharmacologic prophylaxis was $49 \%$ ( $n=98$ of 200), and the mechanical prophylaxis administration rate was 99\% (199 of 200). The rates of mechanical prophylaxis were $98 \%$ (100 of 102) in the trauma service and 99\% (97 of 98) in the non-traumaservice group $(P=0.99)$. Pharmacologic prophylaxis was prescribed more often in the trauma service group, at $54 \%$ (55 of 102), but this was not statistically significantly different $(P=0.16)$ than the $44 \%$ (43 of 98) in non-trauma-service patients. When evaluating each prophylaxis type, mechanical prophylaxis alone (without initiation of pharmacologic prophylaxis) was utilized more often in the non-trauma-service group, at $56 \%$, but this was not statistically significantly higher than in the trauma-service group $(45 \%, P=0.12)$. Administration of pharmacologic prophylaxis alone without any administration of mechanical prophylaxis occurred in $1 \%$ for both groups. The trauma service had more patients that received a combination of both pharmacologic and mechanical prophylaxis during their ICU stay, at 53\%, but this was not significantly higher than the non-trauma-service group (43\%, $P=0.15)$.

Of the patients who were administered pharmacologic prophylaxis, most received enoxaparin only $(73 \%, n=$ $71)$, and $18 \%(n=17)$ received heparin only. One patient (1\%) received apixaban only, and the remainder of the patients $(n=8)$ received some combination of these medications. The most marked difference $(P<0.01)$ between trauma-service and non-trauma-service admissions was that almost all patients admitted to the ICU by the trauma service received enoxaparin only $(95 \%$, $n=52)$, with the remainder receiving heparin only (5\%, $n=3$ ), whereas among non-trauma-service admissions, just $45 \%(n=19)$ received enoxaparin only, and 33\% $(n=14)$ received heparin only. The remainder of the non-trauma-service admissions received apixaban only $(2 \%, n=1)$ or a combination of medications (e.g., enoxaparin followed by heparin, simultaneous enoxaparin and heparin; $n=9$ ). Although not explicitly delineated, higher utilization of heparin in the non-trauma-service group may be related to common reasons heparin is used over LMWH, such as renal dysfunction.

After the initiation of pharmacologic prophylaxis, 10\% of the total cohort had interruptions. Trauma-service patients experienced an interruption $9 \%$ of the time, and non-trauma-service patients experienced an interruption $12 \%$ of the time $(P=0.74)$. When evaluating the two major types of pharmacologic prophylaxis (enoxaparin and heparin), the interruption rates of both drugs were similar between both the trauma-service and nontrauma-service groups $(P=0.99)$.

When assessing delays in the initiation of pharmacologic prophylaxis, the median delay for the two groups combined was $23 \mathrm{~h}$ after ICU admission. The median initiation delay for the trauma service was 53 $\mathrm{h}$, and the median delay for the non-trauma-service group was $10 \mathrm{~h}(P \leq 0.01)$. Delays in initiation were additionally evaluated individually for enoxaparin and heparin. Enoxaparin was initiated a median of $30 \mathrm{~h}$ after ICU admission among the entire study population. Among patients overseen by the trauma service, enoxaparin was initiated a median of $53 \mathrm{~h}$ after ICU admission, and the median for the non-trauma-service group was $17 \mathrm{~h}(P \leq 0.01)$. Heparin was initiated a median of $7 \mathrm{~h}$ after ICU admission among the entire study population. The median initiation time among the trauma service was $131 \mathrm{~h}$ after ICU admission, and the median among the non-trauma-service group was $4 \mathrm{~h}(P=0.03)$.

The most common reason for holding prophylaxis, defined as either administering no prophylaxis or interrupting it after initiation, was discontinuation before a surgical procedure $(46 \%$ of those with interrupted or no prophylaxis, $n=26$ ), followed by recent head trauma with fracture or brain injury (referred to here as traumatic brain injury (TBI) within the previous $48 \mathrm{~h}$ ) (30\%, $n=17)$ and the presence of an active bleed $(30 \%, n=17)$. Nine patients $(16 \%)$ had no documented reason for nonadministration or interruption; all these patients were admitted to the ICU by non-trauma-service physicians. Complications related to VTE prophylaxis administration, including DVT, PE, and bleeding, were rare in the study population. One trauma-service admission (1\%) experienced a PE while in the ICU, and one nontrauma-service admission (1\%) developed severe liver dysfunction.

In adjusted logistic regression analyses using receipt of pharmacologic prophylaxis as the outcome, traumaservice admitting department (odds ratio $(\mathrm{OR})=2.88$, 95\% confidence interval (CI) 1.21-6.83) and increasing ICU length of stay $(\mathrm{OR}=1.13,95 \% \mathrm{CI} 1.05-1.21)$ were significantly independently associated with the outcome (Table 3). When evaluating delays in pharmacologic initiation, defined here as initiation $>48 \mathrm{~h}$ after ICU admission, adjusted logistic regression analyses showed that trauma-service admission $(\mathrm{OR}=8.30,95 \% \mathrm{CI} 2.18$ $31.56)$ and increasing hospital length of stay $(\mathrm{OR}=1.15$, 95\% CI 1.03-1.28) were significantly associated with this outcome. 
Table 2 Venous thromboembolism prophylaxis administration practices in the intensive care unit

\begin{tabular}{|c|c|c|c|c|}
\hline & All & $\begin{array}{l}\text { Trauma } \\
\text { service }\end{array}$ & $\begin{array}{l}\text { Non-trauma } \\
\text { service }\end{array}$ & $P$ \\
\hline & $n=200$ & $n=102$ & $n=98$ & \\
\hline VTE prophylaxis administered & 199 (99\%) & $101(99 \%)$ & $98(100 \%)$ & 0.99 \\
\hline Pharmacologic prophylaxis administered & $98(49 \%)$ & $55(54 \%)$ & $43(44 \%)$ & 0.16 \\
\hline Mechanical prophylaxis administered & 197 (98\%) & $100(98 \%)$ & 97 (99\%) & 0.99 \\
\hline \multicolumn{5}{|l|}{ VTE prophylaxis type } \\
\hline Mechanical only & $101(51 \%)$ & $46(45 \%)$ & $55(56 \%)$ & 0.12 \\
\hline Pharmacologic only & $2(1 \%)$ & $1(1 \%)$ & $1(1 \%)$ & 0.99 \\
\hline Both & $96(48 \%)$ & $54(53 \%)$ & $42(43 \%)$ & 0.15 \\
\hline Pharmacologic prophylaxis administered & & & & $<0.01$ \\
\hline Enoxaparin only & $71(73 \%)$ & $52(95 \%)$ & $19(45 \%)$ & \\
\hline Heparin only & $17(18 \%)$ & $3(5 \%)$ & $14(33 \%)$ & \\
\hline Apixaban only & $1(1 \%)$ & $0(0 \%)$ & $1(2 \%)$ & \\
\hline Heparin, followed by enoxaparin & $4(4 \%)$ & $0(0 \%)$ & $4(10 \%)$ & \\
\hline Enoxaparin, followed by heparin & $2(2 \%)$ & $0(0 \%)$ & $2(5 \%)$ & \\
\hline Enoxaparin, followed by apixaban & $1(1 \%)$ & $0(0 \%)$ & $1(2 \%)$ & \\
\hline Simultaneous heparin and enoxaparin & $1(1 \%)$ & $0(0 \%)$ & $1(2 \%)$ & \\
\hline Interruption of pharmacologic prophylaxis after initiation & $10(10 \%)$ & $5(9 \%)$ & $5(12 \%)$ & 0.74 \\
\hline Interruption of enoxaparin & $8(10 \%)$ & $5(10 \%)$ & $3(11 \%)$ & 0.99 \\
\hline Interruption of heparin & $2(8 \%)$ & $0(0 \%)$ & $2(9 \%)$ & 0.99 \\
\hline Time between admission and pharmacologic prophylaxis initiation (hours), median (IQR) & $23(8-76)$ & $53(15-107)$ & $10(2-25)$ & $<0.01$ \\
\hline Admission to enoxaparin initiation (hours), median (IQR) & $30(14-77)$ & $53(15-95)$ & $17(4-25)$ & $<0.01$ \\
\hline Admission to heparin initiation (hours), median (IQR) & $7(0-29)$ & $131(17-188)$ & $4(0-21)$ & 0.03 \\
\hline Admission to apixaban initiation (hours), median (IQR) & $2(2-2)$ & - & $2(2-2)$ & - \\
\hline \multicolumn{5}{|l|}{ Reasons for non-administration or interruption of prophylaxis } \\
\hline Holding for procedure ${ }^{a}$ & $26(46 \%)$ & $14(67 \%)$ & $12(33 \%)$ & 0.03 \\
\hline Active bleed & $17(30 \%)$ & $8(38 \%)$ & $9(25 \%)$ & 0.30 \\
\hline Recent TBI ( $\leq 48 \mathrm{~h})$ & $17(30 \%)$ & $12(57 \%)$ & $5(14 \%)$ & $<0.01$ \\
\hline High bleeding risk & $3(5 \%)$ & $0(0 \%)$ & $3(8 \%)$ & 0.30 \\
\hline Low platelet count $(<50,000)$ & $3(5 \%)$ & $1(5 \%)$ & $2(6 \%)$ & 0.90 \\
\hline Epidural catheter & $2(4 \%)$ & $2(10 \%)$ & $0(0 \%)$ & 0.13 \\
\hline Intracranial pressure monitor & $1(2 \%)$ & $1(5 \%)$ & $0(0 \%)$ & 0.37 \\
\hline Other ${ }^{b}$ & $13(29 \%)$ & $4(19 \%)$ & $9(25 \%)$ & 0.75 \\
\hline No documented reason for treatment holding or interruption & $9(16 \%)$ & $0(0 \%)$ & $9(25 \%)$ & 0.01 \\
\hline
\end{tabular}

Bold indicates statistically significant results at a threshold of $P \leq 0.05$. VTE venous thromboembolism, IQR interquartile range, $T B I$ traumatic brain injury. a Procedures resulting in prophylaxis holds: ankle fixation, brain biopsy, bronchoscopy, burr hole, coronary artery bypass graft, cardiac repair, craniotomy, endovascular coiling, image-guided percutaneous abscess drainage, inferior vena cava filter placement, massive transfusion protocol, open reduction internal fixation, odontoid screw fixation, removal of epidural catheter, sacroiliac screw fixation, tracheostomy, ulnar repair. ${ }^{\mathrm{b}}$ Other documented reasons for holding: cardiac issues, change in diagnosis, undefined contraindication to pharmacologic prophylaxis, code, diagnosis changed to stroke, INR not reaching subtherapeutic goal, open gastrostomy tube, patient religious objections, transfer to another hospital, and patient-requested withdrawal of care

\section{Discussion}

This study found that in a single, open medical-surgical ICU in a tertiary care non-academic medical center, pharmacologic prophylaxis was not administered at rates consistent with ACCP recommendations by either the uniformly managed trauma service or the nontrauma service. Rates were higher for pharmacologic prophylaxis ordered on patients under the care of the trauma service. Although there were no significant differences in pharmacologic prophylaxis rates between admitting groups, both hovering around $50 \%$, adjusted regression analyses showed trauma-service admission to be a significant predictor of pharmacologic prophylaxis administration. Delayed initiation of 
Table 3 Univariate and independent associations with pharmacologic prophylaxis administration in the intensive care unit

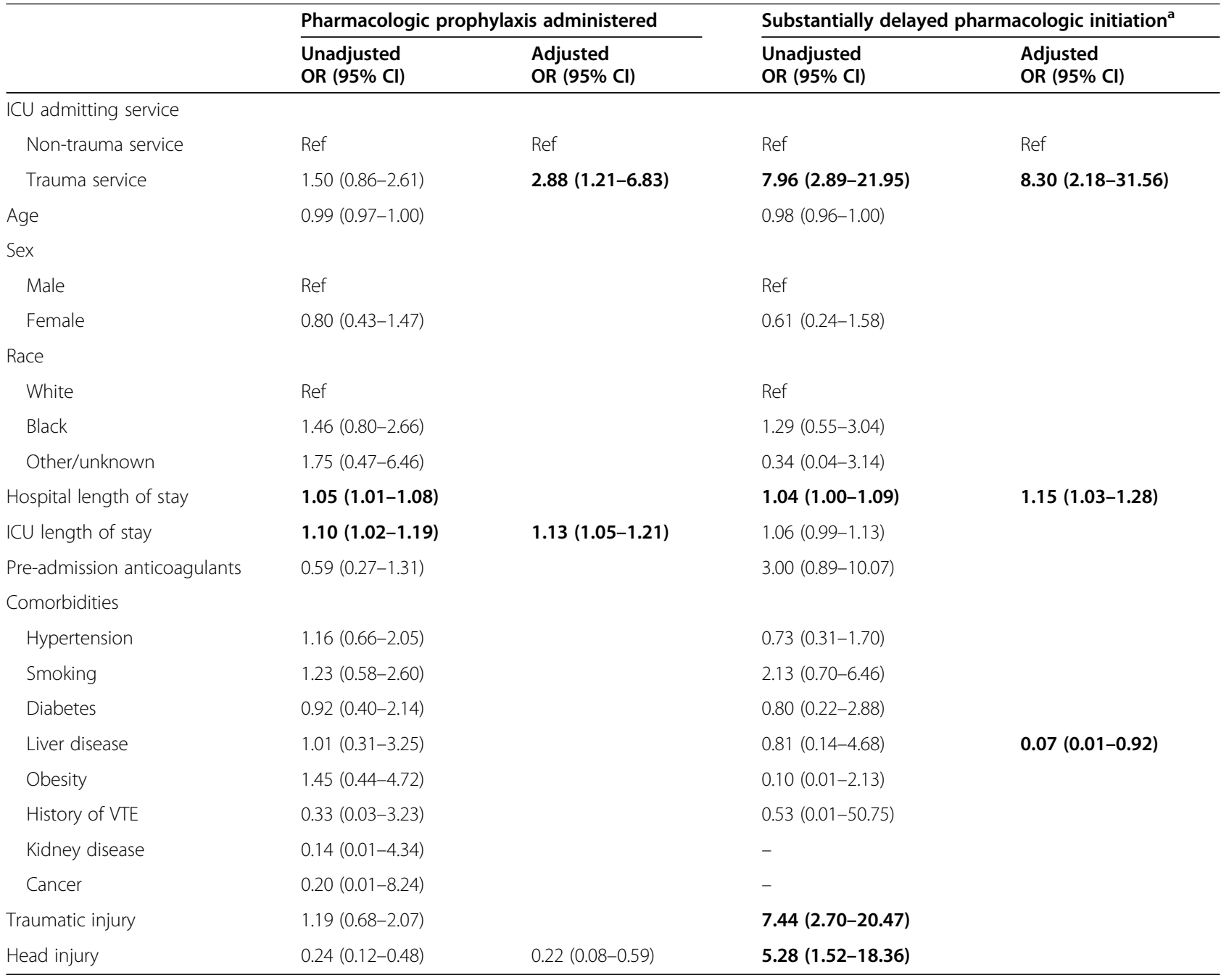

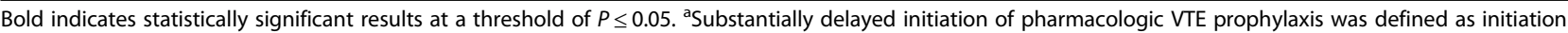
$>48 \mathrm{~h}$ after admission to the ICU. OR odds ratio, 95\% Cl 95\% confidence interval, ICU intensive care unit, VTE venous thromboembolism

pharmacologic prophylaxis was, however, more likely in the trauma group. These results imply that after accounting for patient-level differences between the groups that affected the likelihood of prophylaxis administration (e.g., more patients with TBI in the trauma-service group), patients admitted to the ICU by the trauma service were more likely to receive pharmacologic prophylaxis during their ICU stay.

Because of the lower-than-recommended administration rates across both groups, we further investigated reasons for non-administration or interruption of prophylaxis. The trauma service documented a specified reason $100 \%$ of the time if there was no pharmacologic therapy or an interruption of therapy. Although the duration of the interruption is unknown, the documented reasons for interruption were consistent with standard practice. This differed from the non-trauma patient group, in which $25 \%$ of the instances of non- administration or interruption had no documented reason.

Prior to the study period reported here, the participating facility implemented an automatic order for mechanical prophylaxis on every patient admitted to the ICU, aiming to increase the percentage of patients receiving some type of VTE prophylaxis. This was based on a QI project that demonstrated $\mathrm{a}<50 \%$ rate for any VTE prophylaxis in the ICU. It was not until the automatic ordering of mechanical prophylaxis was instated that prophylaxis rates approached $100 \%$. Not surprisingly, the mechanical prophylaxis rate in the current study was $99 \%$ among the trauma-service patients and $100 \%$ among the non-trauma-service patients. Use of mechanical prophylaxis is part of daily QI on nursing rounds, with "fall outs" reported to attending physicians for rectification. 
Pharmacologic VTE prophylaxis is both indicated for ICU patients and more effective than mechanical prophylaxis. Translating this recommendation into regular practice is challenging. Improving the practice in the trauma service is part of the QI process that has been established. Nonadministration and interruptions of pharmacologic prophylaxis are reviewed regularly on all trauma-service patients. Improving the practice of pharmacologic prophylaxis among non-trauma-service patients will likely require a different approach. One approach would be to close the non-trauma part of the ICU to the non-trauma pulmonary intensivist service. Another approach may be similar to the mechanical prophylaxis order set: making pharmacologic prophylaxis a default, held only for specific contraindications.

One limitation of this study was a small sample size. Because the outcomes of VTE and bleeding complications are infrequent, the sample size did not allow for conclusions about prophylaxis administration and associated outcomes. However, the sample size was sufficient to allow a description of prophylaxis administration practices overall in the ICU and evaluate whether these practices differed between patients overseen by the trauma service and those overseen by non-trauma-service physicians. An additional limitation was the grouping of ICU admissions into those patients admitted to the ICU by the trauma service compared to those admitted by non-trauma-service hospital departments. Patients admitted to the ICU by the trauma service were relatively similar in terms of the primary reason for hospital admission: 93\% of trauma-service admissions were admitted for traumatic injuries. Patients admitted by non-trauma-service departments had wide-ranging reasons for hospital admission, including traumatic injury, neoplasm, infectious disease, and chest pain, among many others. Future work may consider using a more similar patient population as a comparison group.

\section{Conclusions}

Overall, VTE prophylaxis of any type was high in both the trauma and non-trauma service. However, both services underused pharmacologic prophylaxis specifically. Delays in initiation of pharmacologic prophylaxis were more common in patients admitted to the ICU by the trauma service. Despite these delays, rates of patients receiving pharmacologic prophylaxis were higher among those patients admitted and overseen by the trauma service. Additionally, the trauma service commonly documented their reasons for holding pharmacologic prophylaxis and the nontrauma service was less likely to follow this practice.

\section{Abbreviations}

ICU: Intensive care unit; VTE: Venous thromboembolism; ACCP: American College of Chest Physicians; DVT: Deep venous thrombosis; PE: Pulmonary embolism; LMWH: Low molecular weight heparin; QI: Quality improvement GCS: Glasgow Coma Scale; IQR: Interquartile range; TBI: Traumatic brain injury; OR: Odds ratio; Cl: Confidence interval

\section{Authors' contributions}

MJW conceived and designed the study, contributed to data interpretation, wrote the manuscript, contributed vital edits, and approved the final version of the manuscript. DG assisted in study design, assisted in data collection, contributed to data interpretation, contributed vital edits, and approved the final version of the manuscript. ES assisted in study design, performed data analyses, contributed to data interpretation, contributed vital edits, and approved the final version of the manuscript. DB-O assisted in study design, contributed to data interpretation, contributed vital edits, approved the final version of the manuscript, and oversaw the study.

\section{Funding}

No external funding sources were used for this study.

\section{Availability of data and materials}

The datasets used and/or analyzed during the current study are available from the corresponding author on reasonable request.

\section{Declarations}

Ethics approval and consent to participate

This study was approved the Western Institutional Review Board (WIRB). WIRB is registered with OHRP/FDA under IRB registration number IRB00000533, parent organization number IORG0000432. The individual IRB number for this study is 20182931. Because of the retrospective nature of the study, it was granted a waiver of HIPAA and consent for participation by WIRB.

\section{Consent for publication}

Not applicable.

\section{Competing interests}

The authors declare that they have no competing interests.

\section{Author details}

${ }^{1}$ Medical-Surgical Intensive Care Unit and Progressive Care Unit, Research Medical Center, Kansas City, MO, USA. ²Pulmonary and Critical Care, University of Missouri School of Medicine, Kansas City, MO, USA. ${ }^{3}$ Trauma Research Department, Research Medical Center, Kansas City, MO, USA. Injury Outcomes Network and Trauma Research LLC, 501 E. Hampden Avenue, Room 4-454, Englewood, Colorado 80113, USA.

Received: 11 January 2021 Accepted: 16 March 2021

Published online: 25 March 2021

\section{References}

1. Al-Hameed FM. Venous thromboembolism prophylaxis: solutions are in our hands. Ann Thorac Med. 2011;6(3):105-6. https://doi.org/10.4103/1817-1737. 82434.

2. American Heart Association. What is Venous Thromboembolism (VTE)? http://www.heart.org/HEARTORG/Conditions/VascularHealth/ VenousThromboembolism/What-is-Venous-Thromboembolism-VTE_UCM_4 79052_Article.jsp. Published March 2017. Accessed 30 Apr 2020.

3. Malato A, Dentali F, Siragusa S, Fabbiano F, Kagoma Y, Boddi M, et al. The impact of deep vein thrombosis in critically ill patients: a meta-analysis of major clinical outcomes. Blood Transfus. 2015;13(4):559-68. https://doi.org/1 0.2450/2015.0277-14

4. Miri M, Goharani R, Sistanizad M. Deep vein thrombosis among intensive care unit patients: an epidemiologic study. Emerg (Tehran). 2017;5(1):e13.

5. Eck RJ, Hulshof L, Wiersema R, Thio CHL, Hiemstra B, van den Oever NCG, et al. Incidence, prognostic factors, and outcomes of venous thromboembolism in critically ill patients: data from two prospective cohort studies. Crit Care. 2021;25(1):27. https://doi.org/10.1186/s13054-021-03457-0.

6. Key NS, Khorana AA, Kuderer NM, Bohlke K, Lee AYY, Arcelus Jl, et al. Venous thromboembolism prophylaxis and treatment in patients with 
cancer: ASCO clinical practice guideline update. J Clin Oncol. 2020;38(5): 496-520. https://doi.org/10.1200/JCO.19.01461.

7. Torres C, Haut ER. Prevention, diagnosis, and management of venous thromboembolism in the critically ill surgical and trauma patient. Curr Opin Crit Care. 2020;26(6):640-7. https://doi.org/10.1097/MCC.0000000000000771.

8. Stelfox HT, Brundin-Mather R, Soo A, Parsons Leigh J, Niven DJ, Fiest KM, et al. (2019). A multicentre controlled pre-post trial of an implementation science intervention to improve venous thromboembolism prophylaxis in critically ill patients. Intensive Care Med. 2019;45(2):211-22. https://doi.org/1 0.1007/s00134-019-05532-1.

9. Laryea J, Champagne B. Venous thromboembolism prophylaxis. Clin Colon Rectal Surg. 2013;26(3):153-9. https://doi.org/10.1055/s-0033-1351130.

10. Minet C, Potton L, Bonadona A, Hamidfar-Roy R, Somohano CA, Lugosi M, et al. Venous thromboembolism in the ICU: main characteristics, diagnosis and thromboprophylaxis. Crit Care. 2015;19(1):287. https://doi.org/10.1186/ s13054-015-1003-9.

11. Ortel TL, Neumann I, Ageno W, Beyth R, Clark NP, Cuker A, et al. American Society of Hematology 2020 guidelines for management of venous thromboembolism: treatment of deep vein thrombosis and pulmonary embolism. Blood Adv. 2020; 4(19):4693-738. https://doi.org/10.1182/bloodadvances.2020001830.

12. Anderson DR, Morgano GP, Bennett C, Dentali F, Francis CW, Garcia DA, et al. American Society of Hematology 2019 guidelines for management of venous thromboembolism: prevention of venous thromboembolism in surgical hospitalized patients. Blood Adv. 2019:3(23):3898-944. https://doi. org/10.1182/bloodadvances.2019000975.

13. Boonyawat $\mathrm{K}$, Crowther MA. Venous thromboembolism prophylaxis in critically ill patients. Semin Thromb Hemost. 2015;41(1):68-74. https://doi org/10.1055/s-0034-1398386.

14. Ejaz A, Ahmed MM, Tasleem A, Rafay Khan Niazi M, Ahsraf MF, Ahmad I, et al. Thromboprophylaxis in intensive care unit patients: a literature review. Cureus. 2018;10(9):e3341. https://doi.org/10.7759/cureus.3341.

15. Ho KM, Tan JA. Stratified meta-analysis of intermittent pneumatic compression of the lower limbs to prevent venous thromboembolism in hospitalized patients. Circulation. 2013;128(9):1003-20. https://doi.org/10.11 61/CIRCULATIONAHA.113.002690.

16. Dhakal P, Wang L, Gardiner J, Shrotriya S, Sharma M, Rayamajhi S. Effectiveness of sequential compression devices in prevention of venous thromboembolism in medically ill hospitalized patients: a retrospective cohort study. Turk J Haematol. 2019;36(3):193-8. https://doi.org/10.4274/tjh. galenos.2019.2018.0413.

17. Morris RJ, Woodcock JP. Intermittent pneumatic compression or graduated compression stockings for deep vein thrombosis prophylaxis?: a systematic review of direct clinical comparisons. Ann Surg. 2010;251(3):393-6. https:// doi.org/10.1097/SLA.0b013e3181b5d61c

18. Park J, Lee JM, Lee JS, Cho YJ. Pharmacological and mechanical thromboprophylaxis in critically ill patients: a network meta-analysis of 12 trials. J Korean Med Sci. 2016;31(11):1828-37. https://doi.org/10.3346/kms.2016.31.11.1828.

19. Lewis TC, Cortes J, Altshuler D, Papadopoulos J. Venous thromboembolism prophylaxis: a narrative review with a focus on the high-risk critically ill patient. J Intensive Care Med. 2019;34(11-12):877-88. https://doi.org/10.11 77/0885066618796486.

20. Beynon C, Hertle DN, Unterberg AW, Sakowitz OW. Clinical review: traumatic brain injury in patients receiving antiplatelet medication. Crit Care. 2012; 16(4):228. https://doi.org/10.1186/cc11292.

21. Uccella L, Zoia C, Bongetta D, Gaetani P, Martig F, Candrian C, et al. Are antiplatelet and anticoagulants drugs a risk factor for bleeding in mild traumatic brain injury? World Neurosurg. 2018;110:e339-45. https://doi.org/1 0.1016/j.wneu.2017.10.173

22. Sanofi. Lovenox: All Indications. https://www.lovenox.com/treatment-indica tions. Published 2018. Accessed 28 Apr 2020.

23. Nicholson M, Chan N, Bhagirath V, Ginsberg J. Prevention of venous thromboembolism in 2020 and beyond. J Clin Med. 2020;9(8):2467. https:// doi.org/10.3390/jcm9082467.

24. Louis SG, Sato M, Geraci T, Anderson R, Cho SD, van PY, et al. Correlation of missed doses of enoxaparin with increased incidence of deep vein thrombosis in trauma and general surgery patients. JAMA Surg. 2014;149(4): 365-70. https://doi.org/10.1001/jamasurg.2013.3963.

\section{Publisher's Note}

Springer Nature remains neutral with regard to jurisdictional claims in published maps and institutional affiliations.

Ready to submit your research? Choose BMC and benefit from:

- fast, convenient online submission

- thorough peer review by experienced researchers in your field

- rapid publication on acceptance

- support for research data, including large and complex data types

- gold Open Access which fosters wider collaboration and increased citations

- maximum visibility for your research: over $100 \mathrm{M}$ website views per year

At $\mathrm{BMC}$, research is always in progress.

Learn more biomedcentral.com/submissions 